\title{
Our garden heritage is in our hands: protecting yesterday, today and tomorrow
}

\section{Ann Steele ${ }^{1}$}

\section{Abstract}

Heritage organisations take responsibility for the conservation and protection of places and objects deemed in some way significant. That protection usually involves, by necessity, the management of change. In garden heritage, that pace of change can be particularly rapid and unpredictable, with the greater movement of pests and diseases across the world and the impacts of global climate change both acting as particular accelerants in our time.

The heritage sector needs to achieve increased resilience and responsiveness to secure gardens and their plants for future generations, keeping them relevant, and without meaningful loss or diminution. In this article the author explains how the National Trust for Scotland (NTS) understands the plants and places it manages and ensures that Scotland's heritage is clearly visible and ready for the future, however uncertain. The Scottish Government strategy for the historic environment, Our Place in Time, and the related developing Sustainable Investment Toolkit are useful tools in support of understanding and relevance. Practitioners with the right skills to care for this heritage are needed, and initiatives to train and encourage recruitment of garden apprentices and students are described here. The NTS's recognition of changes in the environment and the role of the heritage sector and its potential to benefit society are also shared. The author makes a call to action to work together to demonstrate the power and potential of Scotland's places, in particular its gardens and its plants.

\section{Introduction}

The National Trust for Scotland (NTS) is Scotland's largest and most wide-ranging heritage membership charity. Its charitable purpose is to protect the significant places, objects and stories in its care on behalf of the people of Scotland and to provide access to them, for learning and for enjoyment.

The NTS portfolio is large, varied and scattered across Scotland. Its scope stretches from the care of mountaintop footpaths to island jetties, from lime harling on castles to grazing on battlefields, from huge historic designed landscapes all the way down to pocket-sized museum gardens. The hundreds of thousands of objects in NTS guardianship are found both indoors and outdoors, and include textiles and paintings, wildlife and wildflowers, vines and verbenas. The stories that link to these places and objects are just as varied - duchess to weaver, local printer to international poet - and include pioneer gardeners who established the grand estates and plant collections which continue to thrive; Osgood Mackenzie of Inverewe (Fig. 1) is a prime example of such a pioneer.

While it may sound counterintuitive, the work of the NTS to protect these national assets necessarily involves change and the management of change - at all levels.

${ }^{1}$ Ann Steele is Head of Heritage Gardening Policy at the National Trust for Scotland. 


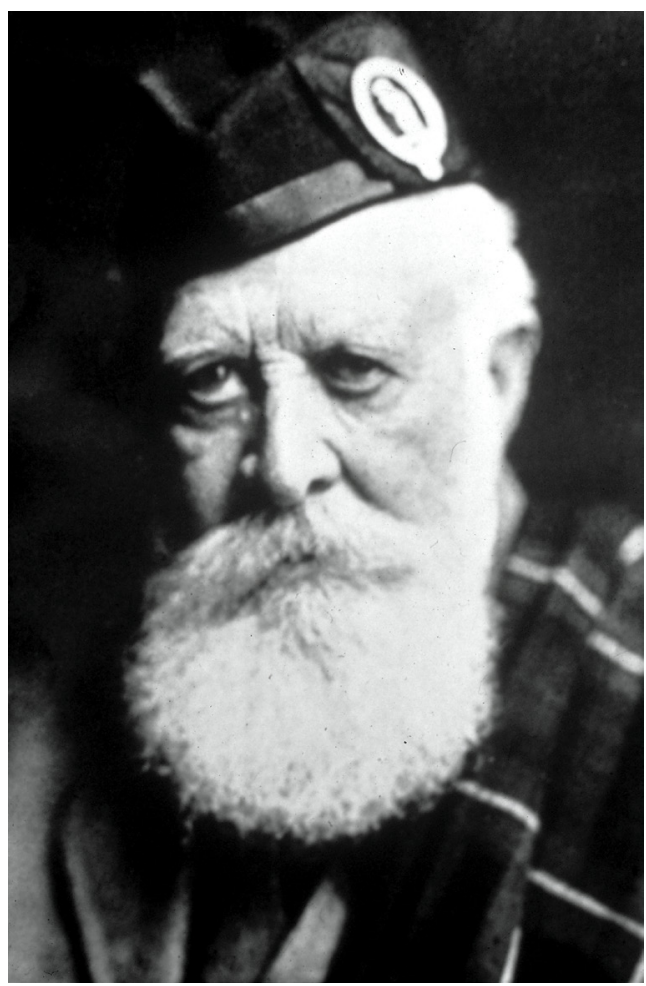

Fig. 1 Osgood Mackenzie, who first created NTS property Inverewe Garden in the north-west of Scotland. Photo: National Trust for Scotland.

\section{Heritage and change \\ Contextual change}

The NTS was formed in 1931 to promote permanent preservation. For most of the intervening years, that activity has been called conservation. More recently, the terminology used has indicated a desire to take responsibility for protecting places, objects and stories deemed in some way significant. A subtle shift in language has taken place, and it is a meaningful one. Significance is a word that carries a load in this context. For many years what was significant, or important, in heritage seemed clear - experts told the NTS and over time the NTS became the experts and told others. That was not wrong, exactly: the NTS has accumulated a lot of detailed knowledge about the things that it cares for. But more recently heritage organisations have realised that, on its own, an expert opinion on significance isn't always enough to justify a place in a collection for an object, a building, a garden or a plant, and nor is it always enough to attract investment in its protection. The sector has had to work much harder at this and challenge itself.

\section{Sectoral change}

Scotland has a Scottish Government strategy for the historic environment called Our Place in Time (or OPiT). This high-level framework sets out a ten-year vision of how Scotland's heritage can be understood, valued, cared for and enjoyed. One strand of work considers how investment in Scotland's built and historic environment might be prioritised through a Sustainable Investment Toolkit (SIT). At first sight this can seem a long way away from managing gardens, but the NTS has been looking at this SIT, and others in the heritage sector may also find it useful to pay attention to this development (BEFS, 2020).

In the future, when the sector is looking for investment from Scottish Government agencies in particular, proposals will likely be weighed and weighted according to the four pillars identified within the SIT:

- Environment: adaptability, condition or environmental benefit

- Society: social benefit, community offer, skills development, engagement or interconnecting places

- Economy: economic benefit, leverage for further investment, financial sustainability or partnership

- Culture: academic value, rarity, significance or at-risk status 
'Significance' - which used to carry so much weight - could in future form only one small section of one pillar.

\section{Changing attitudes}

As competition for investment, support and attention grows, heritage organisations and government see it as increasingly important to make as direct a connection as possible between the work that they do, the people they do it for and the people who ultimately pay for it - be that the people of Scotland, supporters, visitors or donors. The sector increasingly believes that people want and need to see and feel the value of that investment too - the value to their communities, to their local economy or the national economy and to the environment and to see it bring tangible positive impacts wherever possible.

\section{Becoming more engaging}

The NTS already reflects this approach in its Vision: 'Scotland's Heritage is valued by everyone and protected now, and for future generations' (NTS, 2018). As a charity, the NTS relies heavily on memberships, donations and gifts of time by volunteers. To be sustainable it needs to continuously generate new memberships, new donations and new volunteers. To do that it needs people to care about its places, its objects and its stories and the work that it does to look after them. The NTS needs people to visit, to want to experience things for themselves, to get up close, to taste and to touch, to be excited and to want to engage.

'Apple days' are an example of hands-on events which enable people to experience plants and heritage at first hand. On such occasions a wide variety of apples is displayed, there are apple experts on hand who can identify visitors' apple trees and many other apple-related activities are available for all to try. These events provide opportunities for harvesting, pressing, cooking, tasting, learning, eating, buying, planting, pruning, pest and disease identification, care and understanding heritage variety conservation (Fig. 2). Above all, the NTS needs people to feel that the work it does and the things it looks after are relevant in the context of what is close to their hearts - including, increasingly, the climate and the environment.

\section{Changing gardens}

Practitioners in horticulture are all very familiar with the need to manage, to adapt to and to put up with change. From their first days in horticulture, they start to connect to the changing seasons and the fact that this spring is different from last. This change feels exciting - it keeps them on their toes, it keeps them learning. They move to other sites, and find that the plants are different, the people are different, and so they grow and develop as professional horticulturists and colleagues.

Around them fashions will change, and materials of choice come and go. Plants that were once popular are all of a sudden nowhere to be seen. Legislation changes too, and they find emissions are to be reduced, vibrations are to be decreased, licences and training are required, and equipment testing is necessary. New technology arrives, new communication channels arrive - they learn to embrace the world of social media and influencers.

\section{Changing patterns of trade}

There are other new forces at play today, of course, which make that pace of change within heritage gardens such as those of the NTS particularly rapid and unpredictable. Global trade in plants brings new pests and 


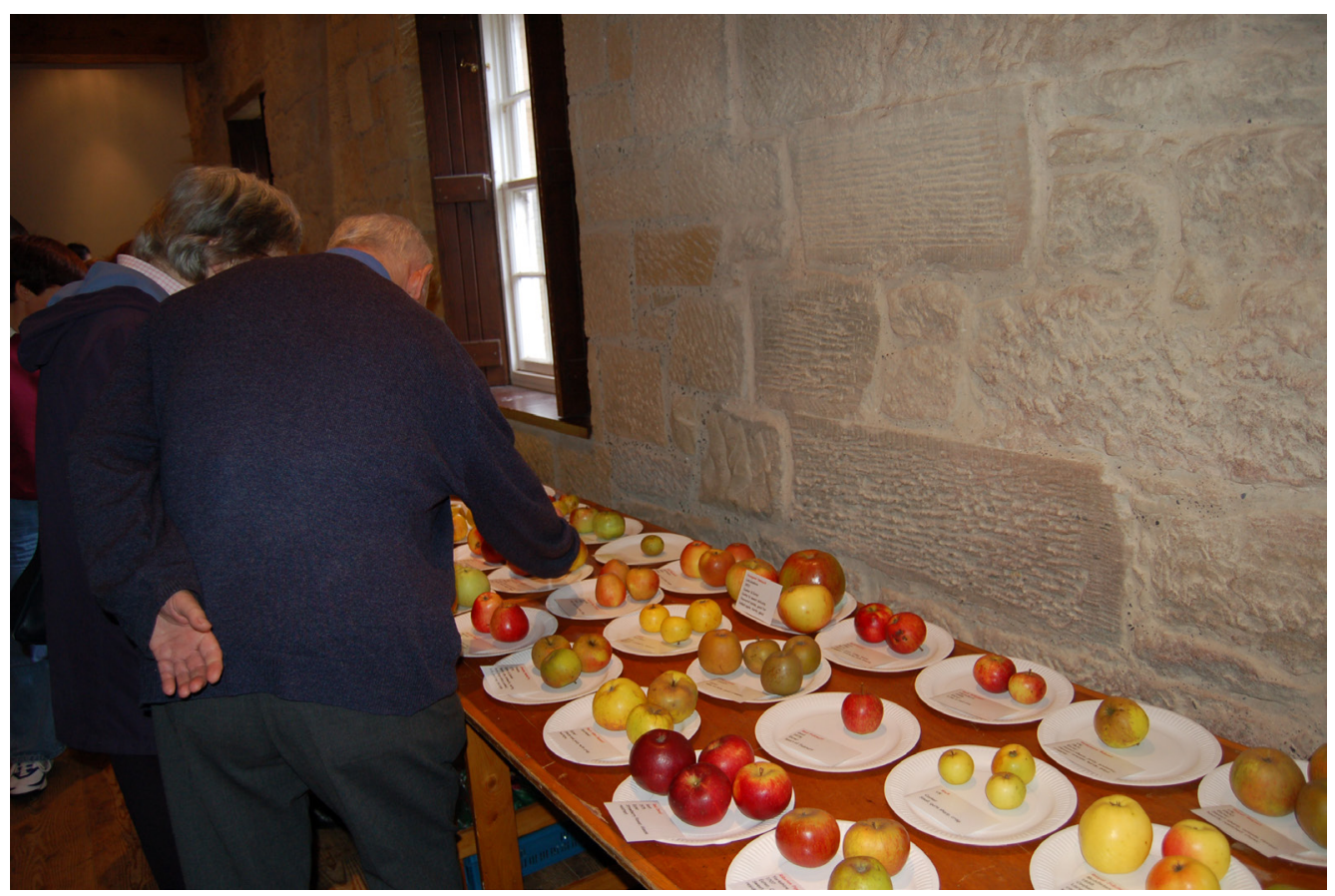

Fig. 2 Heritage apple event at NTS property Culzean Castle, in the south-west of Scotland. Photo: Ann Steele.

diseases to UK shores, and doubtless causes the UK to export them too. The plant diseases caused by Phytophthora ramorum have had a major impact on some gardens (Fig. 3), as for P. kernoviae (Fig. 4) and, more rarely, $P$. lateralis.

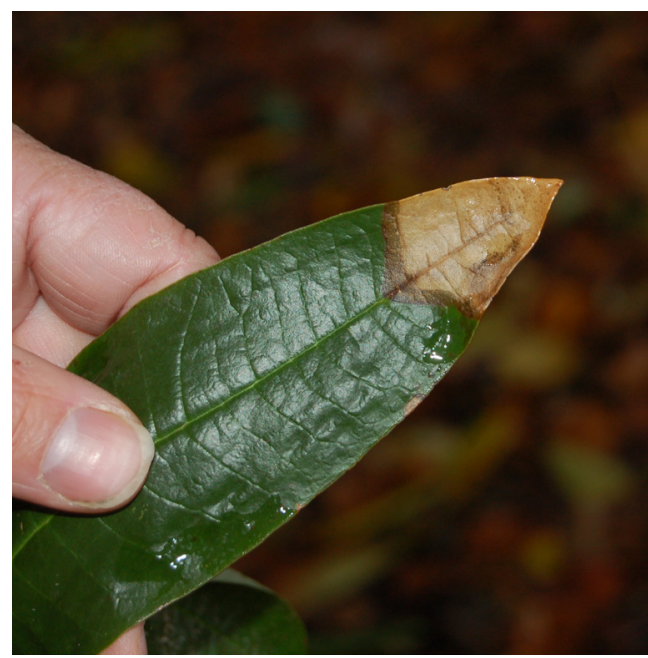

Fig. 3 Phytophthora ramorum leaf infection. Photo: Ann Steele.

\section{Changing climate}

Climate change makes the wider environment more favourable for pests that once lived only indoors. Pulvinaria floccifera (cushion scale), which used to be a glasshouse pest in the south of England, has now become a risk to the wider environment right to the north of Scotland. Even if practitioners want to use pesticides and herbicides, the choice available is becoming more restricted, as they are often too expensive to keep on the market for manufacturers or too environmentally damaging, or have negative impacts on human health.

Climate change affects heritage garden growing environments too. Gardeners always love to test the boundaries of what can grow and thrive in their sites, seeking inspiration across the globe. But as they do this, they need to ensure that the seemingly stable, steady elements of their plant collections 


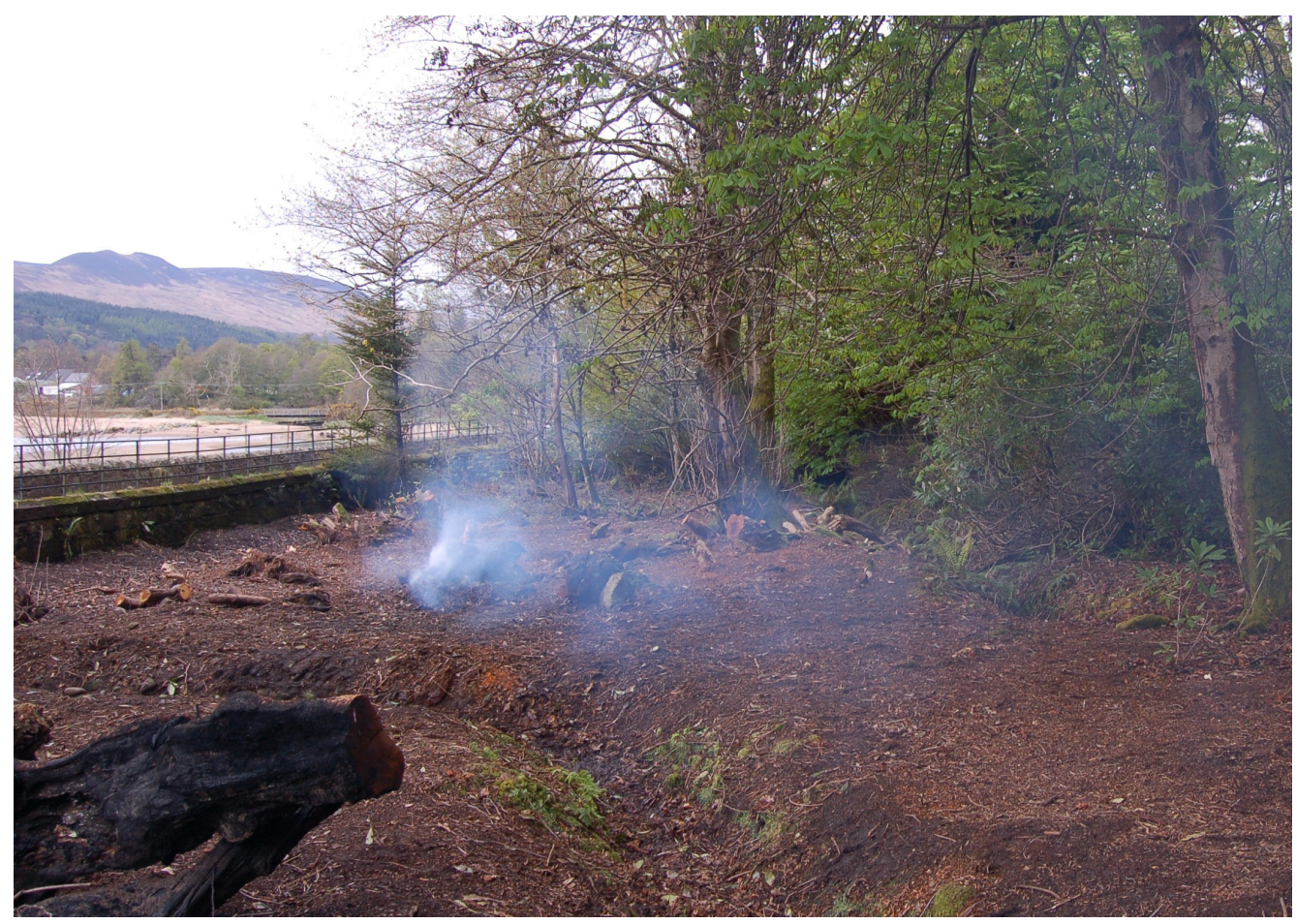

Fig. 4 Clearance work linked to Phytophthora kernoviae infection. Photo: Ann Steele.

are not leaping the fence and polluting the environment as new invasive non-native species. Rhododendron ponticum ('wild' or 'common' rhododendron) has long been a major invasive plant in western areas of the UK. Introduced as game cover and as a rootstock for decorative hybrids, subsequent under-management allowed it to spread and adversely blanket natural habitats. With predictions of climates becoming warmer and wetter, which will favour the rhododendron, that situation is likely to worsen. Lysichiton americanus (American skunk cabbage) too has long spread, in this case along watercourses from gardens and estates down to the coast, dominating them and other damp habitats. A growing host of other 'problem' plants is emerging, including Leycesteria formosa (Himalayan honeysuckle), Griselinia littoralis (New Zealand broadleaf) (Fig. 5) and Rubus spectabilis (salmonberry) to which responsible horticulturists need to be alert.

To care for the sector's special gardens and designed landscapes in the face of the climate emergency professional gardeners will need to get much better at composting and to finally give up that love affair with peat and with plastics that cannot be recycled. But that is just scratching the surface of the changes needed. To justify horticultural activities the sector will have to look at new ways to keep soils and gardens healthy while reducing carbon emissions, becoming familiar with concepts such as embedded carbon and embedded energy, reducing waste and water usage. The sector will also have to adjust its own expectations around the appearance of gardens and designed landscapes and will have to influence visitors too - everyone will need to get used to perhaps a few more weeds and some longer grass. With the NTS 


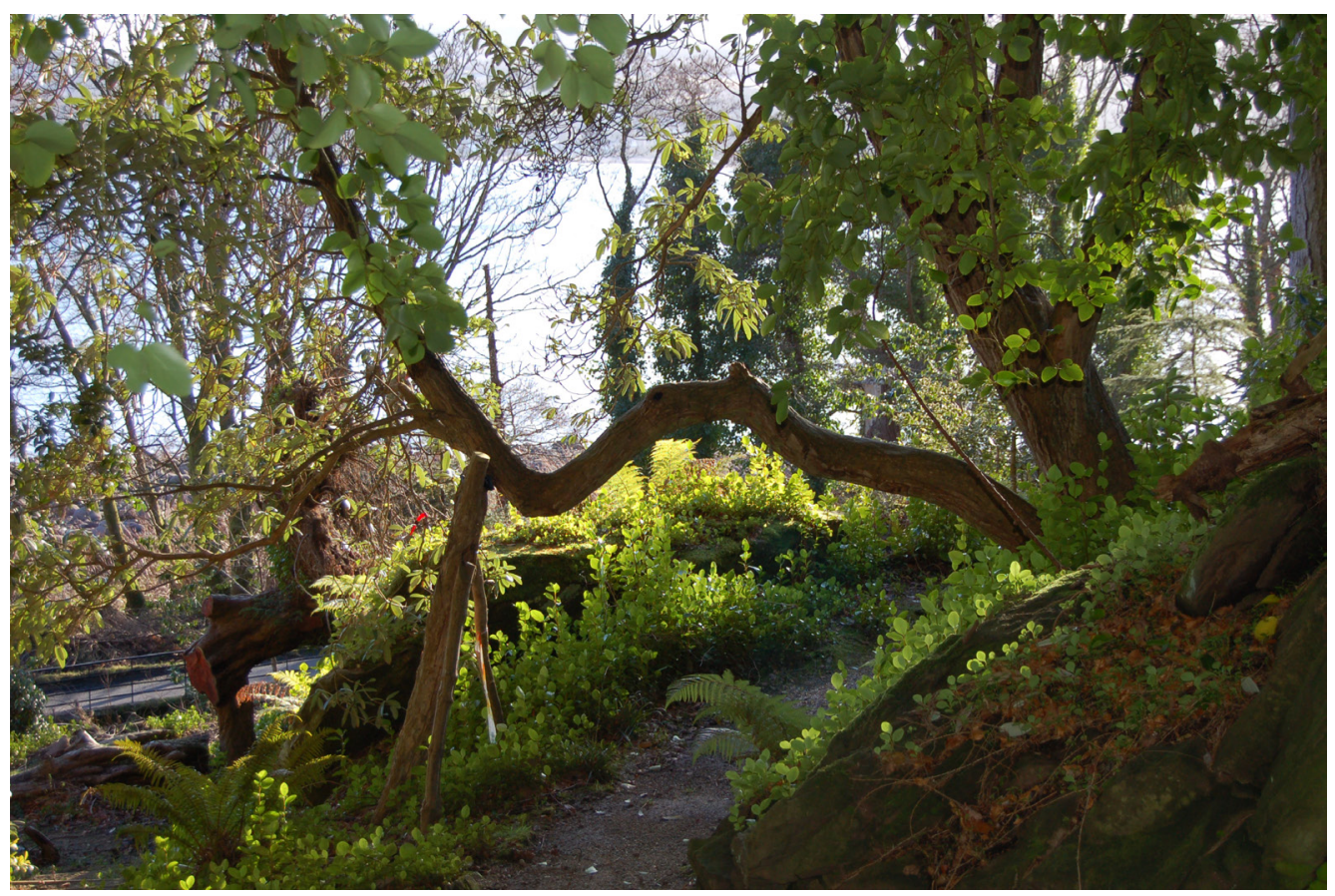

Fig. 5 Self-sown seedlings of Griselinia littoralis. Photo: Ann Steele.

looking forward to its 100th anniversary in 2031, this is the ideal time for it to be setting out how it wants its gardens and designed landscapes to look by then, what condition it wants them to be in and how it wants them to be operating.

\section{Resilience, responsiveness and relevance}

So, given all these challenges, how can the heritage garden sector achieve the increased resilience and responsiveness that it will require to secure its heritage plants and gardens for future generations, keeping them relevant, and without meaningful loss or diminution?

Firstly, the sector needs to communicate well with its audience. It needs to show that it understands its plants and places, that it has teased the golden thread of heritage significance from the past so that it is clearly visible and can be shared, valued and cast forward into the future for succeeding generations in a sustainable way. The NTS does this through documentation and research about its sites, from both its own period of ownership and much further back into history. There is always room for more research, of course, but the NTS needs to be pragmatic and recognise that not everyone who has the power to make changes to its sites will want, or be able, to wade through all the information held about a property and carefully weigh it up. For that reason, the NTS garden management team have been working on synthesising the information already held about its gardens and presenting what its practitioners need to know in a summary document called a Garden Heritage Overview. Its primary purpose is to get to the heart of what any manager needs to know before implementing change, but it also provides an evidence base in support of continued investment in the protection 
of these heritage assets and for restoration proposals.

The NTS has also developed a Conservation Performance Indicator for our gardens, as part of a Conservation Key Performance Indicator for the whole organisation. It is a technical piece and relies on proxy indicators, but over time this measure should help assure NTS Trustees and staff that the organisation continues to conserve its places, objects and stories according to its charitable purpose. Again, this evidence-based approach should bolster bids for resource for conservation work.

Documentation and monitoring are key elements for the NTS, but at least as important as these in managing change is having practitioners with the right skills to care for its plant and garden heritage. The horticultural industry has long lamented its skills shortage, and within the industry there are many truly niche roles such as plant pathologist and propagator, where experience is key.

The NTS had a recruitment crisis in 2016 and 2017 following a spate of retirements. This was tackled initially by an internal rebalancing and evidence from peer organisations leading to an uplift in salaries. However, that was only a partial solution; it made the NTS more competitive, but salaries in the private sector can be at a level well above those of charities and the NTS has to benchmark to other not-for-profit organisations. What the NTS also needed to do was create a pipeline of fresh talent, bringing new people into the horticultural industry who would learn to appreciate what the heritage sector and life in Scotland has to offer. The NTS has developed hundreds of professional horticulturists through its School of Heritage Gardening at Threave Garden in Dumfries and Galloway over the past 60 years, and many have gone on to run gardens and other enterprises across the world. However, having invested in those horticulturists and with those skills in short supply in the marketplace, the NTS has been keen to improve retention and return. This has led to the introduction of a pilot Garden Apprenticeship Scheme, in partnership with the Scottish Rural College at Oatridge, based around a Modern Apprenticeship (MA) which is still the key apprenticeship vehicle in Scotland. The two-year programme is pitched at the MA in Horticulture at SVQ Level 2. The NTS has had two intakes of five trainees (Fig. 6) so far with four from the first intake successfully completing their MA in September 2020, three of whom are still employed within the NTS. Other notable successes saw two apprentices given awards by the Royal Caledonian Horticultural Society. These new entrants are vital to keeping NTS gardens relevant, able to understand those threads of significance and weave them into their management of our special places as we hand them on, into their care.

New entrants are one thing, but the sector also needs to support career progression thereafter, for those who want it. This is an area that needs further development for mid-career gardeners too, with a focus needed on diversity, craft and management skills, and the leaders of the future.

\section{Conclusion}

In the NTS the gardens' interests are spread across the whole organisation but staff work to create links and talk across any potential divides. The organisation maintains documentation about its sites, it has skilled practitioners to manage them and is working to create more skilled practitioners for the future. However, the sector is compact, so 


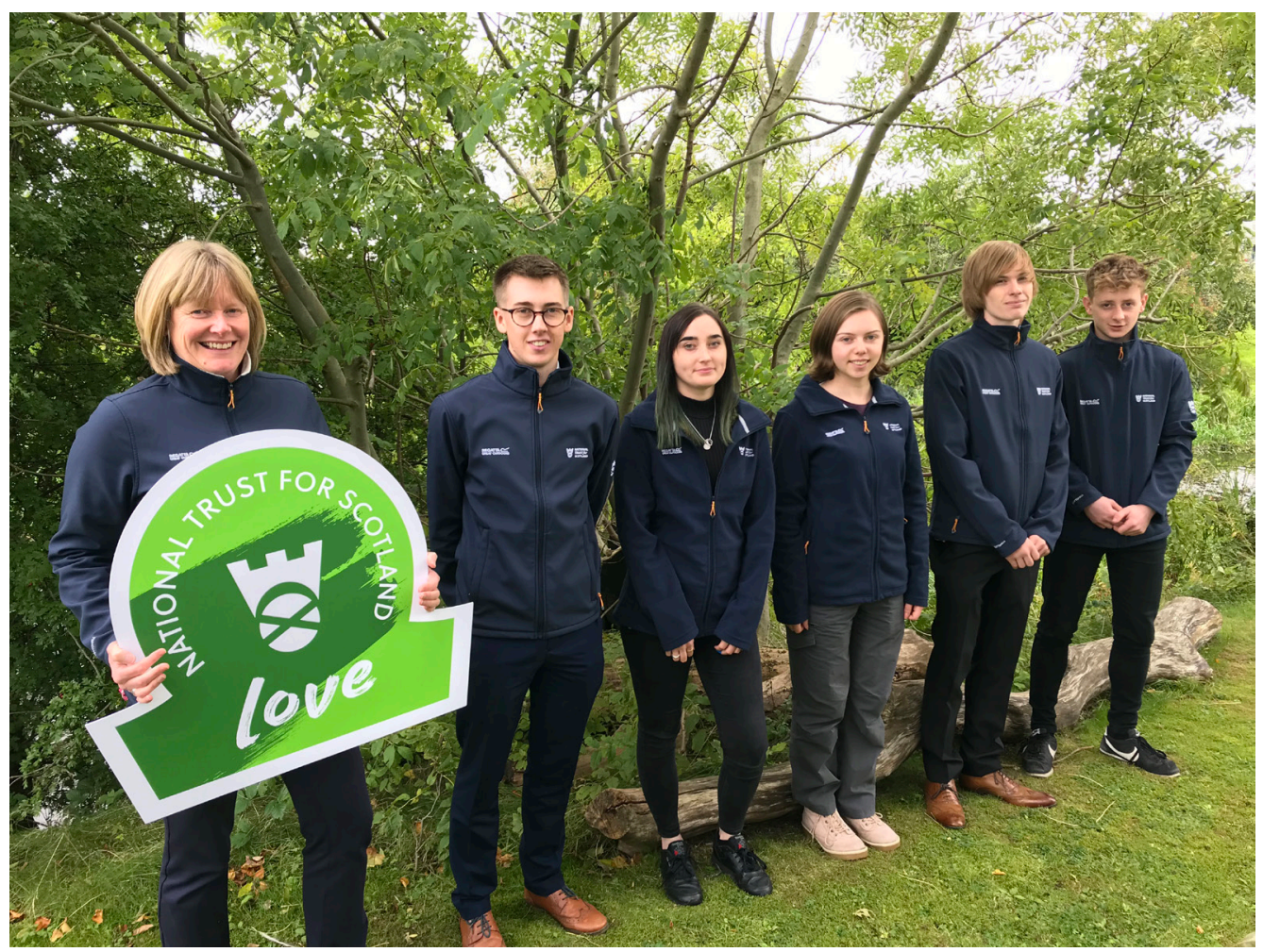

Fig. 6 NTS Garden Apprenticeship first intake 2018. Photo: National Trust for Scotland.

organisations and individuals need to work well together across any areas of competition. Seasoned professionals never tire of saying what a small industry horticulture is, and that's because it is true.

Horticulturists are so busy looking after their places that many just want to keep their heads down and get on with the tasks in hand. During the COVID-19 pandemic that has perhaps been the case more than ever. However, it is all the more important now that everyone takes even a little time out to engage.

It is only by working together through our networks that we can find common cause and solutions to problems for ourselves, for our sector and for horticulture in society, and source partners and support for new ventures. Whether we are looking after old horticulture or developing new, we work in an industry that contributes massively to society and its wellbeing. It is a great sector to work in, protecting yesterday, today and tomorrow.

\section{References}

BEFS (2020). Draft SIT. Complete pack.

Available online: www.befs.org.uk/wp-content/ uploads/2020/05/Draft-SIT-Complete-Pack.pdf (accessed March 2021).

NATIONAL TRUST FOR SCOTLAND (2018).

Our strategy. Available online: www.nts.org.uk/ our-work/our-strategy (accessed October 2020). 